\title{
Virtual Experiments in Collaborative Archival Education: Constructing a Digital Laboratory for Digital Learning
}

\author{
Authors: \\ Karen Anderson, Mid Sweden University \\ Jeannette A. Bastian, Simmons College \\ Andrew Flinn, University College London \\ Göran Samuelsson, Mid Sweden University
}

\section{Short Abstract}

Sustainable archives and preservation education in a global digital society demand collaborative frameworks and multiple, geographically diverse partnerships. This poses considerable challenges for educators. A consortium between archival education programs at University College London, Mid Sweden University and Simmons College, Boston, is addressing these challenges within an innovative virtual learning environment developed, built and shared among the three schools. Participants from each of the three programs describe, analyze and demonstrate ongoing collaboration, research and curriculum development unified through the Digital Curriculum Laboratory (DCL). They also explore the implications of these types of learning resources and collaborative approaches for supporting archives education internationally.

\section{Introduction}

In our increasingly global digital society, it is critical that archives and preservation education look towards creating collaborative frameworks and multiple, geographically diverse partnerships both for sustainability and continued relevance. This 
imperative poses considerable challenges for educators, some of which include the obvious ones of distance, language and communication, while others, more subtle but potentially more pernicious, concern archival education itself. Modes of delivery, content and processes and the expectations of students and employers may vary from country to country. Certainly legislation, record-keeping behaviors and archival cultures are often country-specific.

Three years ago, three archival programs, discovering their mutual interest in developing virtual laboratories for student experimentation decided to explore collaboration across international borders. Initially coalescing around virtual curriculum laboratories under development by two of the partners, the collaboration also began exploring the sharing of courses, the leveraging of technical expertise, and student exchange. This article describes the ongoing process, the issues, and the future challenges of collaborative efforts between the archives and preservation programs at University College London (UCL), Mid Sweden University, and Simmons College in Boston.

\section{Collaborative Beginnings}

\section{Simmons College}

In 2009, archives faculty at the Graduate School of Library and Information Science at Simmons College in Boston, Massachusetts applied for and received grant support to develop a virtual curriculum laboratory for archives and preservation education in which faculty and students could experiment with digital content and tools 
within a curriculum structure. ${ }^{1}$ In terms of furthering archival and preservation education, it seemed clear at that time - and continues to be even more urgent today - that in addition to classroom learning, students needed hands-on experience with digital materials. The Digital Curriculum Laboratory (DCL) was conceived as a virtual "sandbox", a workspace populated with the necessary tools, standards and content, so that its users, primarily graduate students, could experiment with, test and learn how to manage digital materials in digital spaces. ${ }^{2}$ Key requirements for the DCL included security so that users could experiment and work in a safe learning environment, and the use of open-source applications and tools so that the Laboratory could potentially be shared with the wider archival and preservation communities. The conditions under which the DCL would be shared were part of the planning and building process. For testing and evaluation purposes, the initial plan for the DCL included two external United States partners. The potential for international partners always seemed an exciting as well as a logical extension.

In its fundamental design, the DCL was conceptualized with three main components: digital content; tools for describing, preserving and managing this content; and an evolving set of instructional learning modules. Now in its fourth year of development, the DCL has evolved considerably but remained true to the original vision. Utilizing a variety of open-source applications that have been customized for use in the Lab, the DCL uses scenario-building, problem-solving and evaluation exercises to teach students to apply and assess a variety of online archival and preservation applications,

\footnotetext{
${ }^{1}$ Grants were awarded from the National Historic Publications Commission and the Institute of Library and Museum Services. The partners gratefully acknowledge their support.

${ }^{2}$ The public webpage of the Digital Curriculum Laboratory is as http://calliope.simmons.edu/dcl/
} 
procedures and techniques. The design of the DCL is flexible and extensible to allow for the adding of modules and functions as they evolve and to enable students to have opportunities to experiment with and evaluate new applications and developing standards. Restricting applications to open source only was always seen as crucial to the broader use of the DCL by other archival education programs and this proved to be a major advantage in attempting to create international partnerships. At the same time, since security and some measure of privacy are also crucial to the use of the DCL as an educational experimental space, the laboratory has both a public face and a private space. The public face, found at http://calliope.simmons.edu/dcl/ describes the DCL, its history, its partners and its content and invites users to register in order to gain access to the laboratory itself. At the present time, only a member of the Simmons community or one of our partner universities may create an account although the partnership hopes to attract other participants. All applications, exercises, scenarios, and test content installed in the DCL are for use only by registered users. It is also hoped that institutional partners who wish to use the resources of the DCL will contribute to the project in some way. This may be through recommendation of open-source applications; addition of content, scenarios, and/or exercises; and/or evaluations of the site.

Sharing, and collaboration were always a major part of the initial vision, as was the recognition that the concept of digital spaces for digital learning was not unique to the needs of Simmons but that other archival and preservation programs were also developing similar spaces. It was through the discovery of these other efforts that the idea for an international partnership to collaborate on archival education projects was born. 


\section{Mid Sweden University}

Mid Sweden University's proposal for a digital laboratory was included within a larger research and development grant to establish CEDIF (Centrum för Digital Informationsförvaltning (Centre for Digital Information Management)). Funding was obtained as part of the European Union Objective 2 program, through the Swedish Agency for Economic and Regional Growth. Funding partners were the Västernorrland County Council, Härnösand Municipality and Sundsvall Municipality.

Students at Mid Sweden University study through distance learning and it had long been realised that a facility to provide off-campus access to examples of systems and tools they will eventually use in the workplace is essential to their professional learning. Mid Sweden University plans to provide systems and resources for teaching about information architecture, business processes, records management systems (EDRMS), enterprise content management and preservation and storage systems. Most of these systems will be proprietary. Ida Infront is the first vendor to work with Mid Sweden to facilitate access to their EDRMS and e-archive solution for learning and teaching. The system, iipax, comes with a small amount of records about applications for building permits in Sweden which are sufficient for developing a demonstration scenario about workflows. A technician to support the digital laboratory was added to the Mid Sweden development team in July 2010.

Although the initial grant is now completed, it did provide the resources and basis for establishing Mid Sweden University's Digital Laboratory and the opportunity to greatly extend the vision as well as the systems and educational tools available through cooperation with the Simmons DCL. 


\section{University College London (UCL)}

Interest from the staff on the Archives and Records Management program in the Department of Information Studies at UCL (UCL:DIS) in participating in the development of a digital lab grew from the shared realization of the necessity of such hands-on, practical yet safe experimentation in digital environments and with digital tools for students and staff for both teaching and research. Relationships between the three programs, both at personal level and increasingly at an institutional level (in particular the joint Mid Sweden / UCL development of the Standards in Digital Recordkeeping module and the five month secondment in 2011 of Dr Flinn to Simmons GSLIS ${ }^{3}$ observing the development and use of the DCL in teaching at first hand) formed the foundations upon which to build UCL's participation in this work.

This came at a time when program staff at UCL:DIS were engaged in a thorough and on-going review and revision of their Masters programs. An evolution rather than a revolution, nevertheless this review examined all aspects of teaching and learning for professional practice. Among the key changes introduced under the review were the explication of the diverse conceptual frameworks which make sense of the management of archives and records and the application of these frameworks to professional practice; a generally more digitally-aware curriculum that fully reflects the changes and developments in the management of information and cultural heritage; a more blended learning approach to curriculum delivery which enables more learning to take place within digital learning environments; greater flexibility and choice within the program, including allowing students to respond to growing (if not absolute) convergence in the

\footnotetext{
${ }^{3}$ The Allen Smith Visiting Scholar program at the Graduate School of Library and Information Science at Simmons College enabled Dr. Flinn to spend the Spring 2011 semester at Simmons.
} 
information and cultural heritage sectors by taking modules from other professional programs and ultimately, perhaps, from other universities; and finally the internationalization of the curriculum to better reflect the globalization of the professions and the challenges faced.

Many of these changes corresponded closely with the on-going developments at Simmons GSLIS and Mid Sweden, and staff at UCL felt that partnership and participation in the development of the digital laboratory and ultimately in exploring further possibilities for collaborative activity in developing international, digital archival curricula were very important opportunities. As UCL:DIS has no physical laboratory of its own (though as of 2013 it was negotiating the establishment of a fully supported mobile laboratory for teaching and research), UCL staff concentrated on developing digital scenarios and exercises which could be run on either the university's network or on students' personal computers and exploring ways in which the Simmons DCL could be employed in classroom activities and assessments. At this stage UCL's participation in the partnership incorporates student and staff use and feedback on the DCL, the suggestion of further content, packages and standards (particularly perhaps with an international audience in mind) and the development and contribution of new scenarios for the laboratory. A good example of the latter is that with funding from an internal UCL grant, Dr Jenny Bunn and Alexandra Eveleigh developed the DISARM (Digital Scenarios in Archives and Records Management) project. This project tested levels of student knowledge and comfort when operating in digital environments and then piloted scenarios concerning digital accessioning and standards for archival description and record-keeping metadata. These pilots were successful, and after taking into account the 
student evaluation, the scenarios were written up and included in the laboratory for all users of the DCL.

Responding to the on-going changes in the information and cultural heritage professions, the UCL Archives and Records Management program has been through a period of significant development and transformation, seeking to better prepare students for their careers in this new digital world by offering a learning experience which is more international, more digitally aware (in content and in delivery) and more flexible. The partnership with Simmons College and Mid Sweden and the sharing of resources, expertise and teaching materials, though not without its challenges, is a core component of these developments.

\section{Establishing the partnership}

Personal networks, collegiality, knowledge of archives education programs as well as serendipity, are all key elements in building partnerships. Friendships developed between archives faculty at all three institutions were instrumental in establishing an atmosphere of collaboration and trust. Not the least of the elements solidifying that trust was a willingness to share, to put educational gain before individual institution and the understanding that the added value gained through collaboration was an important educational component to be passed on to students. ${ }^{4}$

Through informal discussions at conferences we began to realize that the three of

\footnotetext{
${ }^{4}$ In 2010, the partners produced a presentation and subsequent publication detailing the trust elements in building partnerships, Anderson, Karen, Jeannette Bastian, Ross Harvey, Terry Plum, Göran Samuelsson, "Teaching to Trust: How a Virtual Archives and Preservation Curriculum Laboratory Creates a Global Education Community," Archival Science, 11. 3-4 (2011): 349-372
} 
us shared a common goal. We were fortunate to be able to take advantage of various international meetings and to turn the informal conversations into more formal sessions. As the DCL was being developed primarily in Boston, both Mid Sweden and UCL began to join the discussions and the experimentation. Through Skype as well as other online facilitators, considerable interchange of ideas became possible.

In early 2012, we initiated a Memorandum of Understanding that has now been signed by each university. The MOU establishes "a collaborative project to develop a model for international archival education cooperation that includes cooperating in a Digital Curriculum Laboratory". The collaboration includes the following provisions that relate both to the implementation of virtual laboratories and to a broader international cooperation around archival education:

1. Attempt to share access to servers, software and scenarios, seek to develop joint curriculum, and consult on development strategies and directions. Emphasis will be on collaboration between faculty, staff and students between institutions.

2. Responsibility by each member for providing technical support for their own servers and systems but the technical teams will consult and advise one another.

3. Efforts to arrange face-to-face meetings.

4. A commitment to designing a model for collaborative international archival education and sharing this model among the international archival education community.

5. Efforts to add members from additional geographic regions as the model develops in order to test and expand it. 


\section{Developing and deepening collaboration}

Through the discussions about what we had already done or planned to do in our respective labs and curricula we realized that there were points of intersection and therefore an indication of what each of us could possibly share and utilize from the others in our core offerings. At the same time we recognized and continue to acknowledge the divergences in our curricula and approach. For example Mid Sweden has more of an emphasis on contemporary recordkeeping issues than Simmons, but Simmons was already interested in developing content in this area. Similarly UCL has been developing and interest and expertise in participatory and community-based approaches to archival and recordkeeping practice which are of interest to all the partners. So it was not just a matter of sharing what we had already but also helping each other develop and extend their offering into different yet relevant curricula areas. This is a process of mutual growth and development. Second, the differences over adopting commercial as opposed to open-sourced tools at Simmons is recognized but has not caused any significant difficulties. In fact this is a decision that is largely dependent on differences in internal IT support rather than a basic philosophical difference. Indeed Mid Sweden investigated the adoption of open source tools but discovered that they did not have the IT support resources to adequately develop and sustain open source approaches and ensure their availability to students at all time.

The relationship between the three partners is a complex interplay between sharing different approaches and responding to the need to develop teaching materials in response to the fast moving and ever changing technological environment in which recordkeepers operate. Such concerns and initiatives are clearly not confined to the 
institutions described here. For example in 2011 a meeting held in Boston on digital curriculum laboratories included the institutions covered by the MoU plus representatives from the Universities of Arizona, North Carolina at Chapel Hill, Michigan, WisconsinMilwaukee, Texas and Pittsburg. ${ }^{5}$ There is no obstacle to thinking about and encouraging wider partnerships with these institutions and any others also interested in developing international collaborative approaches to archival education.

\section{Future Challenges}

While the initial focus has been on lab infrastructure with a concentration on preservation scenarios and exercises, the partners need to work to provide exemplars and exercises for the entire records continuum, including information architecture, metadata management and business process analysis for records capture, registration and archival description. Equally important as the structure and content are the management and the policies of these shared virtual spaces. Criteria for new content, criteria for additional partners, joint use and sharing policies, classroom and curricula collaboration - these are just a few of the outstanding issues that the partnership must consider next.

Additionally, there are the challenges arising from the internationality of the partnership itself. To what extent is language a limiting factor? Although the interface has been translated into English, Swedish content in iipax, for example, limits usability for students who do not understand Swedish. How difficult will it be to overcome technical incompatibilities? What about time and university calendar differences, cultural

\footnotetext{
${ }^{5}$ Archival Education and Research Institute (AERI) Pre-conference Meeting on Digital Curriculum Labs, Simmons College Boston July 2011
} 
outlooks and behaviors? And finally, there are the differences and divergences within the archival discipline across nationalities. How universal is archival theory and how similar is archival practice across international borders? Is there compatibility between archival education curricula? These pressing and difficult questions, particularly those around curricula and national traditions are the ones that form the basis of on-going exploration and research between the partners of the MoU. ${ }^{6}$ These are only the most obvious challenges, but we anticipate others. Key to their resolution is a mutual understanding of the need to collaborate and work together as participants in a global information society. One of the many advantages of this kind of collaboration is the opportunity to study and understand more closely the variety and diversity of the archival discipline itself as we find ways to broaden our education and give new archivists access to the international perspectives and knowledge that they will require to succeed in the future.

\footnotetext{
${ }^{6}$ Anderson, Bastian and Flinn, 'Mapping international core curricula', International Congress on Archives Section for Archival Education and Training Pacific Conference, 3rd Asia and Pacific Conference on Archival Education Beijing 23-24 October 2013
} 